\title{
Life-time Characteristics of Random Wound Compressed Stator Windings under Thermal Stress
}

\author{
Mehmet C Kulan ${ }^{1 *}$, Nick J Baker ${ }^{2}$ \\ ${ }^{1,2}$ School of Engineering, Newcastle University, Merz Court, Newcastle Upon Tyne, United Kingdom \\ *mehmet.kulan@newcastle.ac.uk
}

\begin{abstract}
Compression of windings is known to give thermal and performance benefits. The aim in this paper is to investigate how stator winding insulation system is influenced by on-tooth coil pressing. A set of compressed coils have been aged by exposing them to high temperatures. Winding insulation resistance is monitored during this process to experimentally validate whether compressed coils are healthy in terms of electrical insulation. In this case, a single stress (i.e. temperature) model is used to predict the reliability of the compressed coils. Accelerated life tests have been conducted to inspect the life expectancy and thermal endurance of the compressed stator coils. The employed statistical model (Arrhenius-Weibull) demonstrates that on-tooth coil pressing reduce the life expectancy dramatically due to reduced turn to ground wall insulation dielectric strength.
\end{abstract}

\section{Introduction}

Recent manufacturing methods and advancements in material science might offer great improvement in the electro-thermal performance of permanent magnet (PM) electrical machines. Due to increasing $\mathrm{kW} / \mathrm{kg}$ of electric motors, high power density machines are only possible with enhanced cooling systems [1]. Power losses in PM electrical machines require a thermal management. Therefore, implementation of different cooling techniques such as water/oil cooling jackets, totally enclosed fan cooling (TEFC) or direct cooling are essential for high power density machines. Despite active cooling techniques keeping materials within their thermal rating, thermal degradation is inevitable for electric machines. Every component of the electrical machine is subjected to degradation due to a number of stresses during the operation [2]. The common aging factors for the electrical machines are temperature, electrical frequency, high voltage and vibration etc. In addition, ambient conditions such as humidity and surrounding temperature are of importance regarding the degradation of insulation within the machines. All these elements cause aging since the first day in service and affect the machine life time expectancy significantly. For this reason, machine designers are anticipated to pay more attention to the reliability modelling in the early stage of the design to offer a longer service life for the final product.

In the literature, one of the proposed methods to manage the power losses in stator windings is pre-pressing the coils as previously reported in [3-6]. The method offers a significant improvement in the slot fill factor and so it helps improve the average thermal conductivity between the winding and the slot wall. Thus, the machine with pressed windings not only drops the winding temperature due to a higher effective heat conduction but also it serves to reduce copper $\left(I^{2} \mathrm{R}\right)$ losses due to a lower electrical resistance that is a function of temperature.

Coil pressing can be easily adapted when the stator is modular and each single tooth winding can be compressed at high pressures (250 - 350 bar) via a hydraulic press. Fig. 1 shows how to support and press the lateral faces of a modular coil by using high strength steel punches.

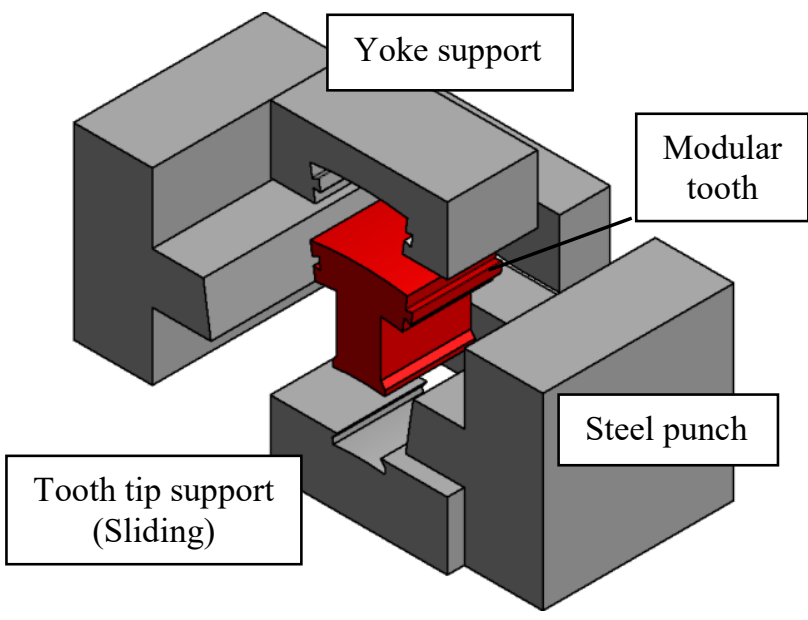

Fig. 1. Overview of the pressing tool for a modular tooth

The reliability of coil pressing is not clear in terms of stator winding electrical integrity. Mechanical deformation on magnet wire enamel and slot insulation system might result in reduced life expectancy in the compressed stator windings as reported in [7].

There are two principal winding insulation systems in rotating machines: turn to turn insulation and ground wall insulation. Mechanical and thermal stresses due to magnetically induced vibration and $I^{2} R$ losses in windings might cause in-service failure because of turn to turn short and/or ground wall short between the conductors and the grounded stator core [8]. Since the compression of stator windings can lead to plastic deformation on magnet wires as reported in [9], the life expectancy of compressed windings might be affected by the compression process. Therefore, thermal aging tests (i.e. single stress aging model) of compressed windings have been carried out to investigate if there is a rapid insulation degradation in stator windings in comparison to conventional random wound coils.

The operating temperature of a winding causes thermal stress due to copper losses and core losses. The expected life of the insulation will be shorter when machine is run at over operating temperature. For this reason, the aging process can be sped up to obtain a life data in a much shorter time if accelerated aging tests are performed [8]. 


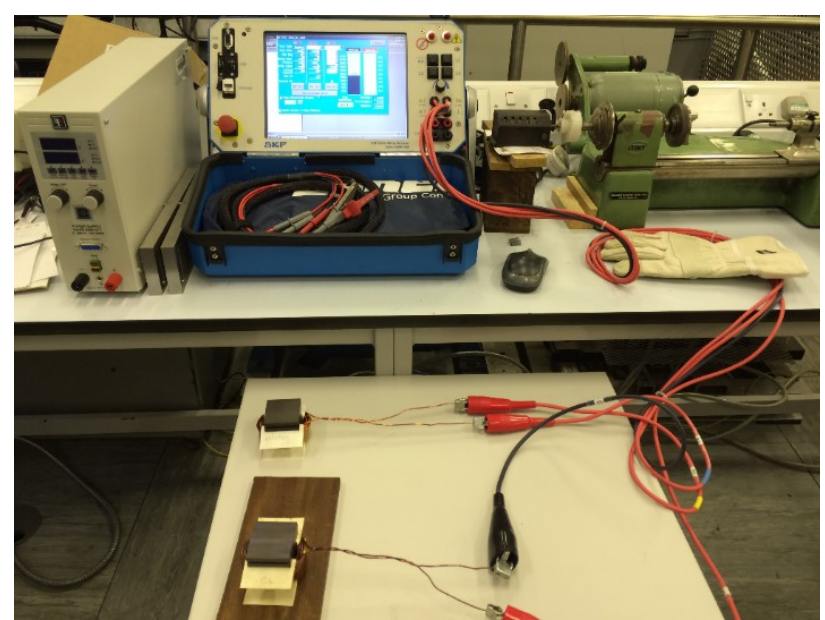

Fig. 2. Static Motor Analyser - Baker Instrument

The Arrhenius life-stress model is one of the most common life-stress relationship utilised in accelerated life testing when acceleration variable is temperature $[8,10]$.

In this work, by choosing at least two over operating temperature, a set of compressed coils which are almost identical in terms of applied pressure, number of turns and insulation system are aged in an environmental chamber operating at up to $180^{\circ} \mathrm{C}$. During the aging tests, off-line stator winding tests including insulation resistance (IR) and high voltage surge tests have been conducted using a 'Static Motor Analyser - Baker Instrument' to record the failure time interval of each particular winding sample by testing coils periodically as depicted in Fig. 2. Thus, the life time characteristics of random wound compressed stator windings under thermal stress have been obtained via an accelerated life test model.

\section{On-tooth Compressed Coils of an Integrated Starter Generator for HEVs}

In order to employ an accelerated life test model for compressed coils, a V-shape interior PM integrated starter generator (ISG) for hybrid electric vehicles (HEVs) has been considered $[5,11]$. The crankshaft mounted ISGs usually expose high surrounding temperature and abrupt temperature variations due to proximity to an internal combustion engine (ICE) and vehicle driving cycles, respectively. Therefore, this application requires a reliability modelling if the insulation system is physically modified by compression.

\subsection{ISG Configuration}

Key machine parameters are shown in Table 1. Size constraints imposed by the existing drive train require the use of a high torque density machine to meet the maximum torque required in the available space.

Table 1 Key ISG parameters

\begin{tabular}{|c|c|}
\hline Outer diameter & $290 \mathrm{~mm}$ \\
\hline Shaft diameter & $150 \mathrm{~mm}$ \\
\hline Active length & $40 \mathrm{~mm}$ \\
\hline Generator power at $2000-5000 \mathrm{rpm}$ & $22 \mathrm{~kW}$ continuous \\
\hline Maximum DC link & $350 \mathrm{~V}$ \\
\hline
\end{tabular}

\begin{tabular}{|c|c|}
\hline $\begin{array}{l}\text { Motor mode torque at } 200 \mathrm{rpm} \text { for } \\
10 \mathrm{~s}\end{array}$ & $180 \mathrm{Nm}$ \\
\hline $\begin{array}{l}\text { Surrounding temperature (Drive train } \\
\text { ambient temperature due to ICE } \\
\text { proximity - generating mode }\end{array}$ & $95^{\circ} \mathrm{C}$ \\
\hline $\begin{array}{l}\text { Surrounding temperature (Cold start } \\
\text { worst case scenario) - Motoring } \\
\text { mode }\end{array}$ & $-30^{\circ} \mathrm{C}$ \\
\hline Cooling system & $\begin{array}{l}\text { Liquid/Water Jacket } \\
\text { with } 6 \text { litre/min }\end{array}$ \\
\hline Coolant temperature (liquid) & $80^{\circ} \mathrm{C}$ \\
\hline
\end{tabular}

The ISG configuration has been optimised in finite element analysis software (FEA) using a parametric model to meet the requirements given in Table 1 and the initial conductor fill factor was chosen to be approximately $70 \%$ since the coils were designed for pressing when they are built. The 2D ISG electromagnetic FE model on no load is also shown in Fig. 3 which has been later used for different thermal investigation scenarios in a $3 \mathrm{D}$ thermal FE software.

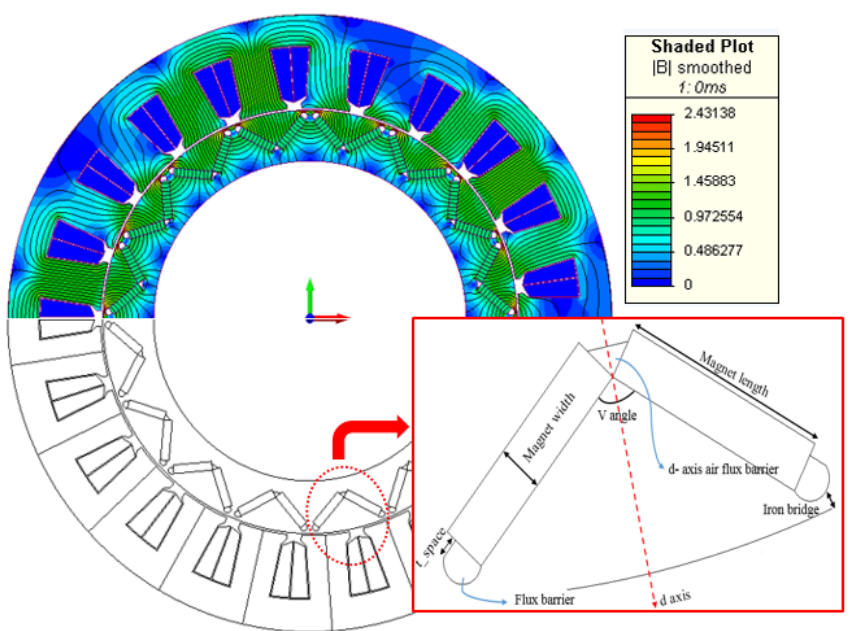

Fig. 3. 21 slot-16 pole V-shape interior PM ISG on no load

For the design of $\mathrm{V}$-shape PM rotor, iron bridge thickness, magnet $\mathrm{V}$-angle, flux barriers, magnet width and length are important optimisation parameters to obtain high reluctance torque and airgap flux density. The parametrically optimised machine dimensions are given in Table 2 in which stator slot dimensions are also included.

Table 2 General machine dimensions

\begin{tabular}{|c|c|}
\hline Stator inner diameter & $200.7 \mathrm{~mm}$ \\
\hline Rotor outer diameter & $198.7 \mathrm{~mm}$ \\
\hline Magnet V-angle & $130^{\circ}$ \\
\hline Distance of V-angle from the shaft centre & $84.2 \mathrm{~mm}$ \\
\hline Magnet bridge thickness & $1.12 \mathrm{~mm}$ \\
\hline Magnet length & $4 \mathrm{~mm}$ \\
\hline Tooth width & $19.5 \mathrm{~mm}$ \\
\hline Tooth tip length & $2.5 \mathrm{~mm}$ \\
\hline Slot opening & $7 \mathrm{~mm}$ \\
\hline Stator yoke thickness & $15 \mathrm{~mm}$ \\
\hline Bare slot area & $388 \mathrm{~mm}$ \\
\hline ISG active mass without shaft & $14.1 \mathrm{~kg}$ \\
\hline
\end{tabular}


The machine consists of segmented single tooth windings with 91 turns. The round conductor diameter is $1.25 \mathrm{~mm}$ and the stator windings are based on Grade 2 polyester-imide coated magnet wires with a thermal class of $200{ }^{\circ} \mathrm{C}$. The stator coils for a phase were connected in parallel and the number of parallel paths are chosen to be 7 .

\subsection{Compressed Coils for the ISG}

The compressed coil specimen at about 0.72 slot fill factor was cut into two pieces to macroscopically investigate the deformation on the magnet wires as shown in Fig. 4(b) (iii). The cross-sectional view indicates that the magnet wires are packed in a smaller volume in a quasi-hexagonal manner. It is anticipated that the thermal contact conductance between the compressed magnet wires increases due to the reduced air voids between the wires. Also, a significant plastic deformation occurs in the compressed windings and its insulation system - Nomex 410 , as the enamelled copper conductors have been permanently deformed.

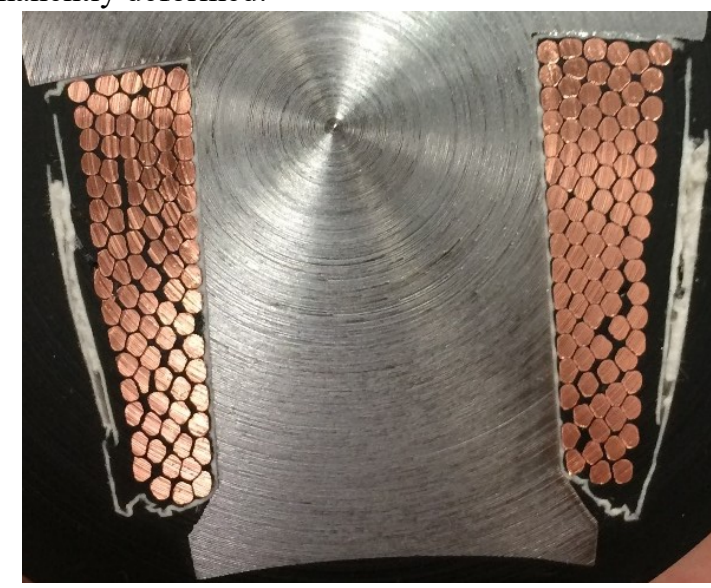

(a)

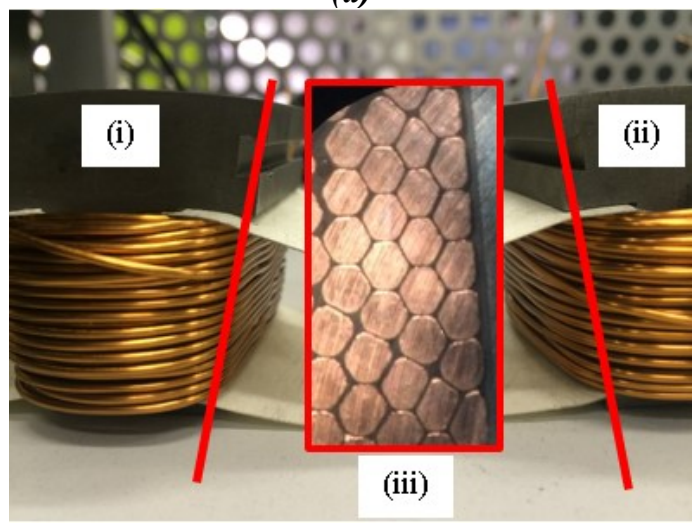

(b)

Fig. 4. (a) Cross-sectional view of a compressed ISG coil ; (b)(i) Compressed coil at 0.72 fill factor, (ii) random wound coil at 0.57 fill factor, (iii) cross-sectional view of the compressed coil

In Fig. 4, it is clear that compression of the coils improves the slot fill factor and this is expected to reduce temperature in the windings. The thermal improvement has been studied in Section 3 .

\section{Thermal Performance of Compressed ISG Windings}

\subsection{Average Slot Thermal Conductivity}

The thermal resistance between the equivalent copper and laminations, $R_{e q v}$ is the most critical thermal parameter since inaccurate evaluation of this resistance results in wrong temperature prediction by thermal models [12]. The traditional way of estimating $R_{e q v}$ is to perform a steady state thermal test through supplying the machine with a DC voltage when only stator Joule losses are active. This method requires a comprehensive calibration process, where temperature in the stator lamination, winding and the machine frame have to be measured.

A simple and fast evaluation of determining equivalent thermal resistance of stator winding can be achieved by short time transient thermal tests. It is based on following hypothesis [13]:

- Over short time thermal transient, the stator lamination temperature can be considered constant.

- The thermal resistance of stator lamination is negligible in comparison to winding insulation system. (i.e. lamination thermal resistance is relatively very small)

- In very small amount of time $(5-10 \mathrm{sec})$, the stator winding system can be considered as adiabatic system.

Short time transient thermal tests have been conducted to measure the equivalent thermal conductivity of compressed windings by assuming a first order (RC) thermal lumped parameter (LP) model for a coil and its insulation system. The average slot thermal conductivity was calculated after finding the equivalent thermal resistance between the winding and slot wall.

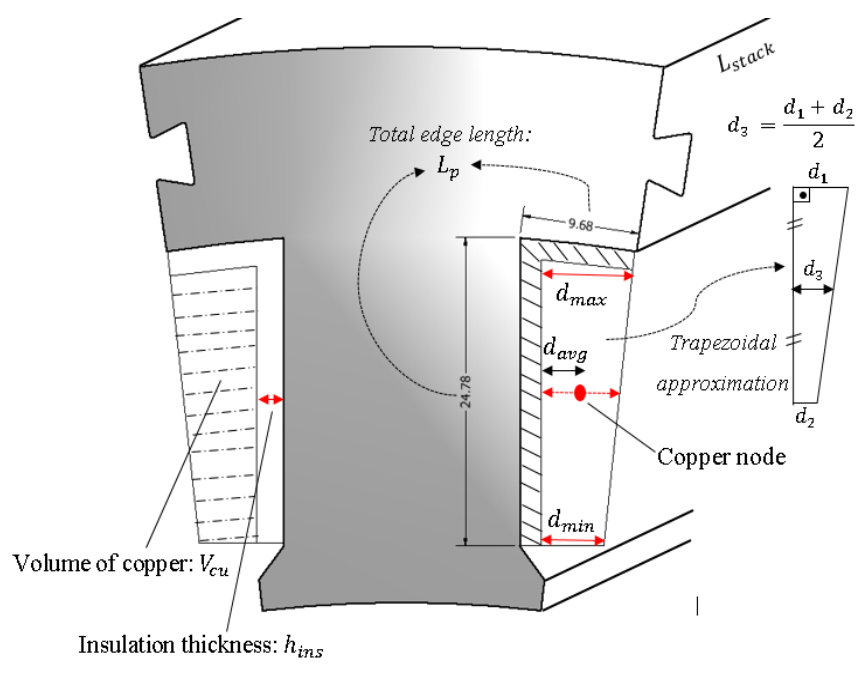

Volume of insulation: $V_{\text {ins }}$

Fig. 5. Geometrical quantities for determination of equivalent slot thermal conductivity

In Fig. 5, a stator segment of 21 slot -16 pole Vshape PM ISG is shown with some geometrical quantities required for the effective thermal conductivity calculation of the winding. An analytical approach has been developed to set a relationship between slot fill factor and thermal conductivity. The derivations are based on a thermal resistance between the centre of the slot (shown as Copper node in Fig. 5) and slot wall. The effective volume of the insulation (slot liner and magnet wire coating) is considered to be a barrier between the copper and laminations with a certain thickness of $h_{\text {ins }}$ as shown in Fig. 5. The simple thermal resistance, $R_{t h}$ can be written in the form: 


$$
R_{t h}=\frac{l}{k A}
$$

In (1), $l$ is the length of the sample $(m), A$ is the cross-sectional area of the sample $\left(\mathrm{m}^{2}\right)$ in the direction of one dimensional heat flow and $k$ stands for the thermal conductivity in $\mathrm{W} / \mathrm{m} \cdot \mathrm{K}$. This equation can be re-written for one side of the ISG coil in (2) with the given dimensions in Fig. 5 as a function of conductor packaging factor. It is described in the following equations:

$$
R_{\text {copper }}=\frac{d_{\text {avg }}}{k_{c u} L_{p} L_{\text {stack }}}
$$

where $k_{c u}$ is copper thermal conductivity $(400 \mathrm{~W} / \mathrm{m} \cdot \mathrm{K})$ and $L_{p} L_{\text {stack }}=A_{c u}$ is lateral surface area of equivalent copper in the slot. $d_{\text {avg }}$ represents the distance between the copper thermal node and equivalent insulation system as shown in Fig. 5.

$$
R_{\text {ins_eqv }}=\frac{h_{\text {ins }}}{k_{\text {eqv_ins }} L_{p} L_{\text {stack }}}
$$

In (3), $R_{\text {ins_eqv }}$ describes the thermal resistance between the equivalent copper volume and slot wall, same as given in (1). $k_{\text {eqvins }}$ is the representation of the equivalent thermal conductivity of the slot barrier formed by Nomex 410 and polyester-imide wire enamel as their thermal conductivities are similar: $\left(k_{\text {Nomex }}=0.14 \mathrm{~W} / \mathrm{m} \cdot \mathrm{K}\right.$ and $k_{\text {enamel }}=0.25 \mathrm{~W} / \mathrm{m} \cdot \mathrm{K}$ ). That is, the insulation barrier can be considered to be a composite of the thermal insulation materials.

$$
\begin{gathered}
\text { Copper cross - sectional area }=K_{w b} \times \frac{A_{s l}}{2} \\
=d_{\text {avg }} \times 2 \times L_{t} \\
d_{\text {avg }}=\frac{K_{w b} \times A_{s l}}{4 L_{t}}
\end{gathered}
$$

where $K_{w b}$ is slot fill factor and $L_{t}$ is slot depth. The equivalent thermal resistance for a single side of the tooth is given

$$
R_{\text {slot_left }}=R_{\text {slot_right }}=R_{\text {copper }}+R_{\text {ins_eqv }}
$$

By using equations (3), (4), (5) and (6), the equivalent thermal resistance for each side of the slot is in the form

$$
R_{\text {slot_left }}=\frac{K_{w b} A_{\text {sl }}}{4 L_{t} k_{\text {cu }} L_{p} L_{\text {stack }}}+\frac{h_{\text {ins }}}{k_{\text {eqv_ins }} L_{p} L_{\text {stack }}}
$$

Then, the equivalent thermal conductivity of the slot insulation barrier is written

$$
k_{\text {eqv_ins }}=\frac{h_{\text {ins }}}{\left(R_{\text {slot_left }}-\frac{K_{w b} A_{\text {sl }}}{4 L_{t} k_{c u} L_{p} L_{\text {stack }}}\right) \times L_{p} L_{\text {stack }}}
$$

In equation (8), it is explicit that increasing the slot fill factor, $K_{w b}$ boosts equivalent thermal conductivity of the slot insulation system. $R_{\text {slot_left }}$ must be known to compute $k_{\text {eqvins }}$. This can be computed by applying a first order RC lumped model for the ISG coil as given in Fig. 6. $R_{\text {slot_left }}$ must also consider the air (i.e. inhomogeneity of the winding region due to air voids). For this reason, the first order RC lumped parameter model based on thermal experiments is necessary.

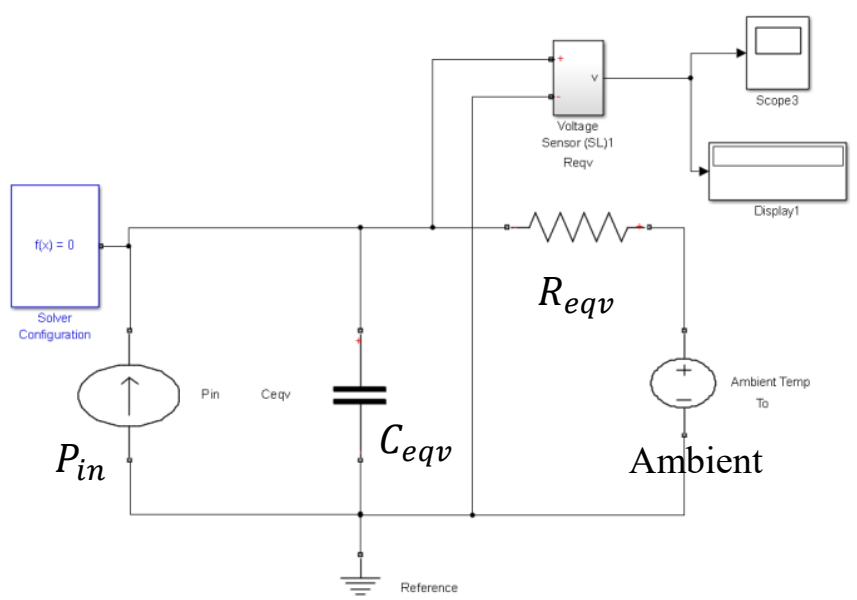

Fig. 6. Geometrical quantities for determination of equivalent slot thermal conductivity

$R_{e q v}\left({ }^{\circ} \mathrm{C} / \mathrm{W}\right)$, the thermal resistance between the equivalent winding and laminations, can be obtained from the thermal time constant, $\tau$ of short time transient tests, which is in the form:

$$
\tau=R_{e q v} \times C_{e q v}
$$

where $C_{e q v}\left(\mathrm{~J} /{ }^{\circ} \mathrm{C}\right)$ is equivalent thermal capacity of the winding and its insulation system. $C_{e q v}$ can be calculated by using motor design data. $R_{\text {eqv }}$ can be computed by two variable minimisation, targeting to minimise the least square error between first order RC model and the short time thermal transient tests. It should be noted that $R_{\text {eqv }}$ cannot be directly substituted to equations (7) and (8) as they considers one side of the slot in which power dissipation $\left(\mathrm{I}^{2} \mathrm{R}\right)$ is half of the full injected power. Therefore, one side of the coil $\left(R_{\text {slot_left }}\right)$ can be estimated to be double the first order RC equivalent thermal resistance, $R_{\text {eqv }}$. This is valid when a single segmented tooth coil is tested with a known DC current as illustrated in Fig. 7.

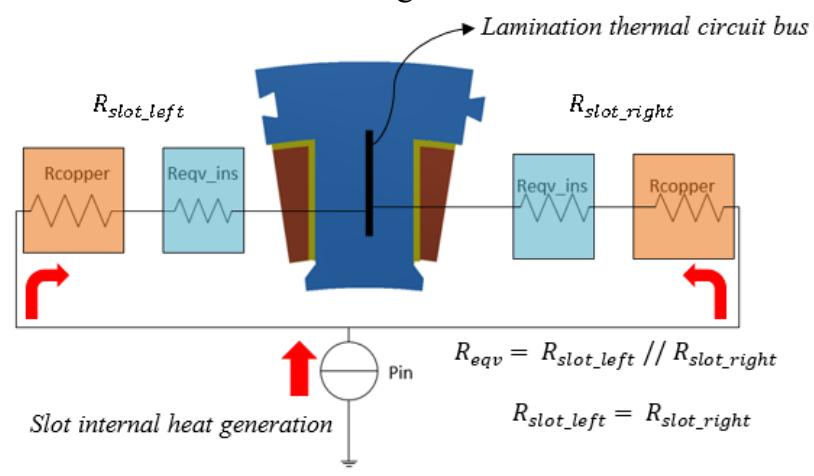

Fig. 7. Equivalent slot thermal resistance for single tooth winding

By using the approach explained above, the equivalent slot thermal conductivity and equivalent thermal resistance for an LP model can be obtained. 


\subsection{Results for the ISG Compressed Coils at Different Slot Fill Factors}

The random wound ISG coils have been compressed at 14 and 20 tonnes and short time transient thermal tests have been conducted. Slot thermal resistance of the ISG coils is determined by matching the experimental transient thermal results to first order RC thermal circuit model of the coils. The results are given in Fig. 8.

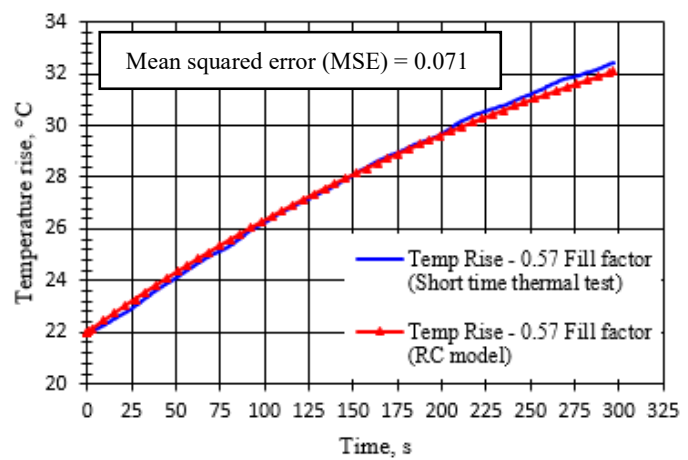

(a)

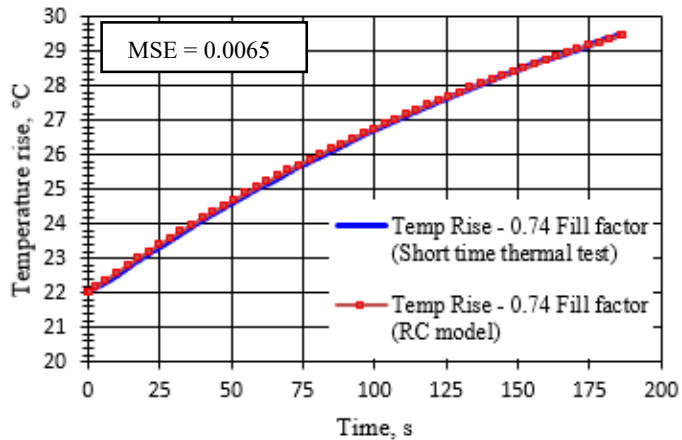

(b)

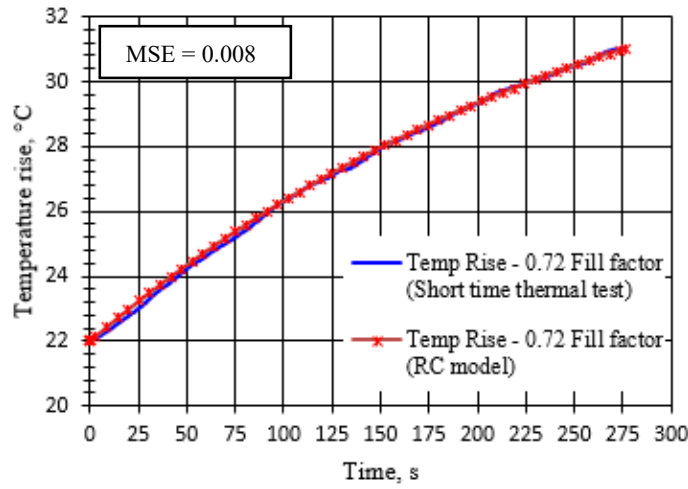

(c)

Fig. 8. Obtaining the first order thermal time constants via least square minimisation between $R C$ model and short time thermal transient tests

The transient temperature rise curves shown in Fig. 8 are used to determine the thermal time constants of the coils. This enables to find experimental $R_{e q v}$ of the coils using the equation (9). The thermal experiments have been extended to find the steady state temperature difference between the winding and slot wall. Fig. 9 summarises the overall experimental results of the coils at three different slot fill factors. However, it is clear in Fig. 9 that the higher the applied pressure, the smaller the thermal resistance between the winding and tooth. Thus, improved thermal properties are demonstrated in compressed windings.

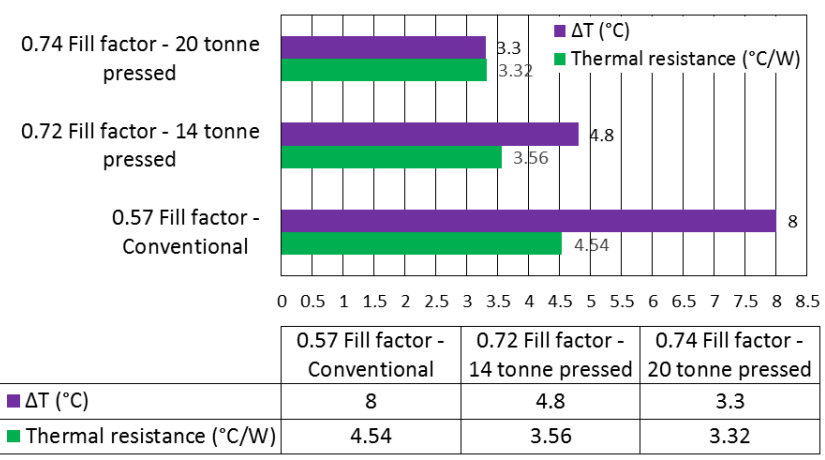

Fig. 9. The effect of applied pressure on the slot thermal resistance and winding to slot wall temperature difference

Compression of the coils to 0.74 slot fill factor however damages the pressing tool as shown in Fig. 10 since the pressure applied reaches 20 tonnes, which permanently deforms the tool made up of EN3B grade steel. The coils are therefore pressed to 0.72 slot fill factor for the further thermal aging experiments to prevent possible experimental problems.

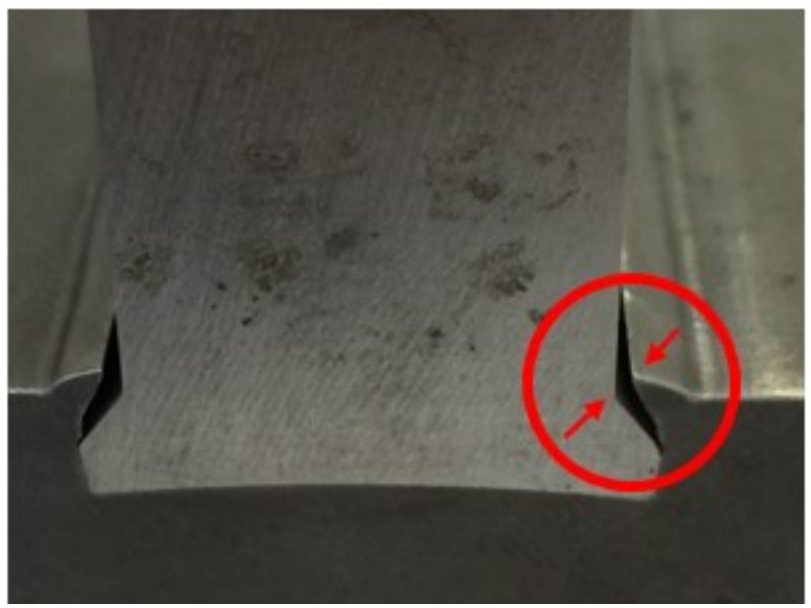

Fig. 10. Plastic deformation in the compression tool made up of EN3B steel after applying 20 tonnes of pressure

Since only the coils compressed to 0.72 fill factor have been considered for thermal life time tests as will be detailed in the rest of the paper, their thermal properties are tabulated in Table 3 .

Table 3 Important slot thermal parameters at 0.72 slot fill factor

\begin{tabular}{|c|c|c|}
\hline $\boldsymbol{R}_{\boldsymbol{e q v}}$ & $\boldsymbol{C}_{\boldsymbol{e q v}}$ & $\boldsymbol{\tau}$ \\
\hline 3.566 & 80.7 & 287.3 \\
\hline
\end{tabular}

$\boldsymbol{R}_{\text {eqv }}$ of the compressed coils is crucial thermal parameter in terms of the accuracy of slot model in thermal FE simulations. The equivalent insulation barrier in the $3 \mathrm{D}$ slot model was calibrated to $\boldsymbol{R}_{\boldsymbol{e q v}}$ such that the equivalent insulation barrier as illustrated in Fig. 5 leads to a temperature difference similar to that obtained in thermal experiments. The calibrated thermal FE analysis for single tooth windings results in temperature rises as shown in Fig. 11 when $4 \mathrm{~A}$ direct current is applied for 2-hours to achieve steady state. The variation in copper electrical resistance has 
been taken into account [5] whilst time varying internal heat generation is applied in the coil FE models to provide accuracy in terms of heat dissipation.

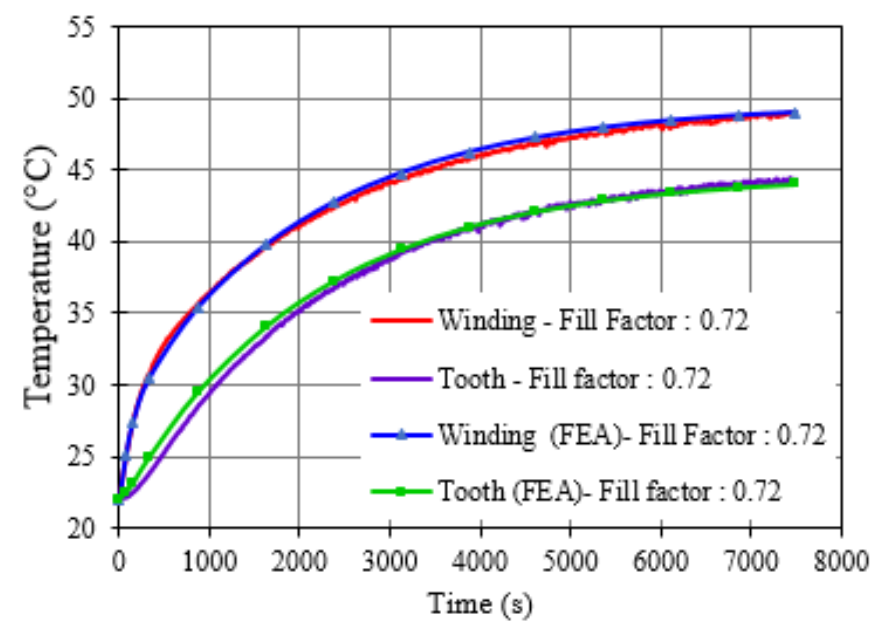

Fig. 11. Temperature rise comparison between the $3 D$ FE model and thermal experiments for a single tooth winding only

Although thermal FE simulations require extensive thermal calibration for the parameters such as thermal contact conductance between the segments and thermal resistance between the stator yoke and frame etc. as reported in [14], the thermal setup in this paper does not investigate the sensitivity of those parameters since it is not the main focus regarding the life time characteristics of the compressed coils.

21 modular ISG bobbins with known slot thermal properties at 0.72 slot fill factor are combined to get the full 3D machine geometry.

3D transient thermal FEA simulations have been conducted to compare hot spot temperature increase in the random wound coils and the compressed coils. Thermal boundary conditions for the performed FEA simulations are based on empirical formulations as given in [15-18]. The FE models are identical in terms of internal heat generation (total losses $=908$ Watts) and thermal boundary conditions (convection coefficients, ambient temperature, water jacket etc.) yet the effective slot thermal resistance (only sensitive parameter) in the $3 \mathrm{D}$ FE model is based on first order $\mathrm{RC}$ thermal model as described extensively in Section 3.1.

The steady state temperature rises of the ISGs at 0.57 and 0.72 fill factors are given in Fig. 12 assuming the surrounding temperature is $95^{\circ} \mathrm{C}$ and a water jacket cooling system with a temperature of $80^{\circ} \mathrm{C}$. Water cooling is applied as a boundary condition directly onto the stator external surface for the simplicity.

Thermal simulations have been performed just to demonstrate the temperature rise in the stator windings and they may not represent the real thermal behaviour of the full machine since previously reported empirical convectional heat transfer coefficients have been used in external surfaces for thermal analyses. Also, the rotor hub does not have adequate conductive heat paths on contrary to the real life.

As shown in Fig. 13, the hot spot winding temperature at 0.57 slot fill factor is $26.1^{\circ} \mathrm{C}$ higher than that at 0.72 slot fill factor. Therefore, it is clear that the ISG with the compressed windings stays cooler than the ISG with the random wound coils at lower fill factors.

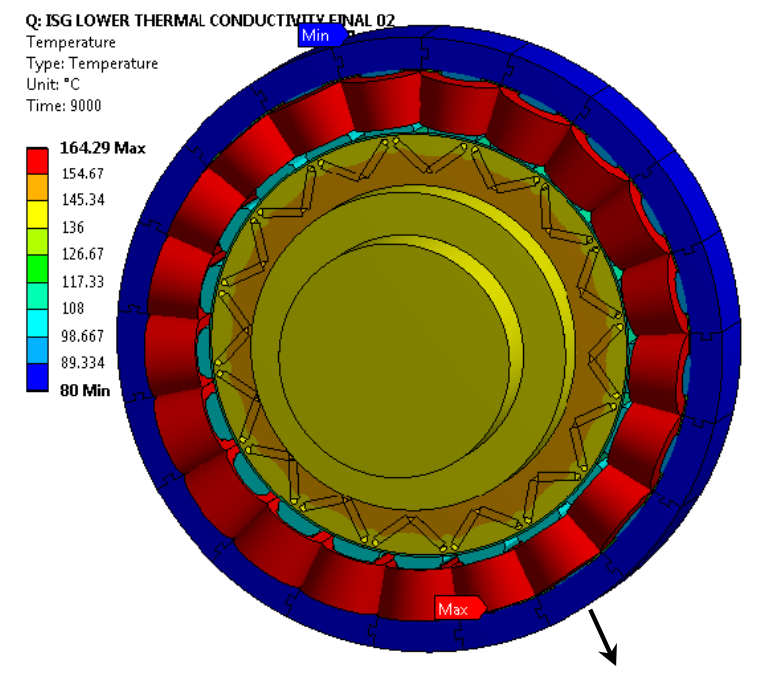

(a)

$80^{\circ} \mathrm{C}$ water jacket cooling on stator

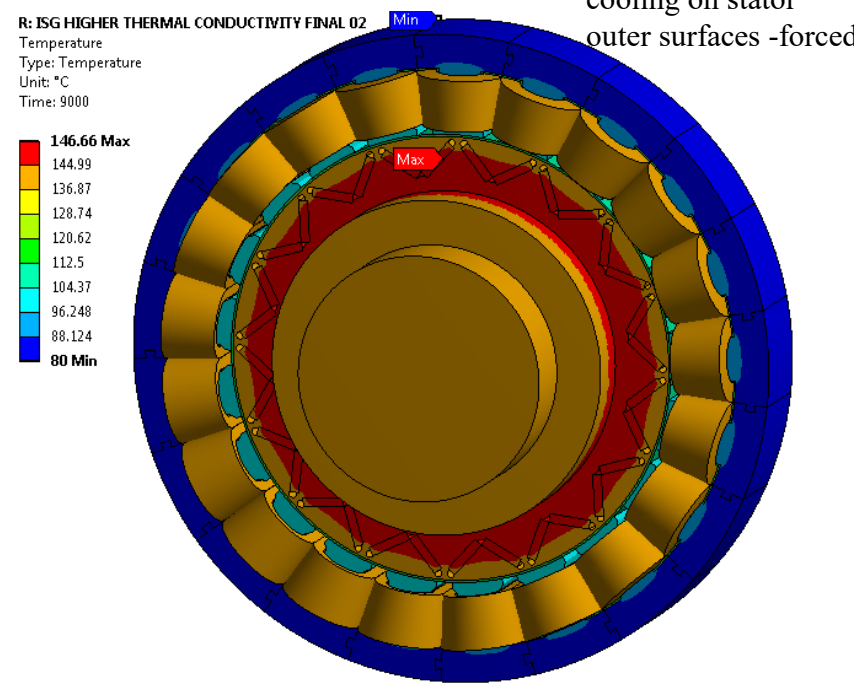

(b)

Fig. 12. Temperature rise in the ISGs at steady state: (a) for the conventional random wound coils; (b) for the compressed coils

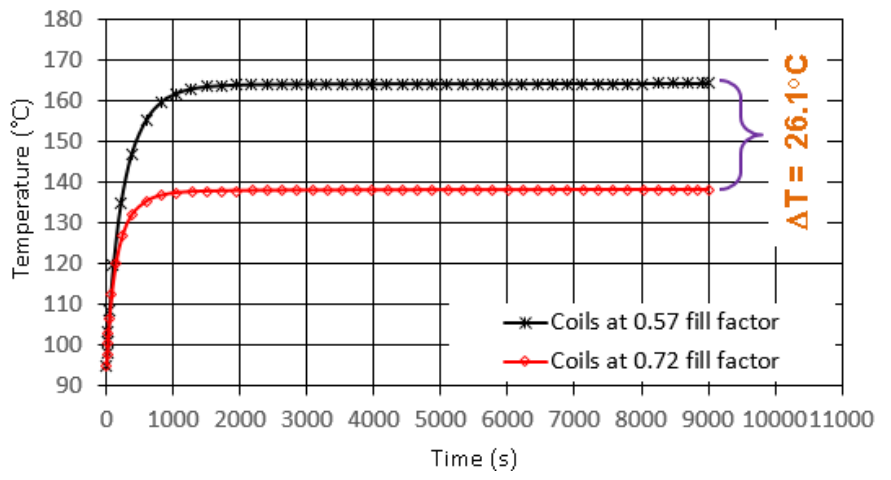

Fig. 13. 3D-FE temperature variations in the ISG coils at 0.57 and 0.72 slot fill factors

To sum up, it is explicit that the thermal performance of the compressed windings is significantly better than random wound single tooth windings yet the insulation system (i.e. magnet wire enamel and $0.25 \mathrm{~mm}$ thick Nomex 410 slot liners) damage (i.e. plastic deformation) on the compressed coils is not clear after the compression of the coils by means of a hydraulic press. 


\section{Insulation Dielectric Strength Tests}

IEEE 43-2000 identifies minimum values for insulation resistance of rotating machines. This standard states that for most machines built after 1970 with random wound stator coils rated below one $\mathrm{kV}$, the minimum insulation resistance is five mega-ohms [19]. All of these minimum values are based on a winding temperature of $40^{\circ} \mathrm{C}$.

Mega-ohm tests are carried out to detect insulation resistance (IR) between windings and ground wall. If any insulation weakness exists between the coil windings and ground, high leakage current is detected during the tests. According to IEEE 43, insulation resistance measurement is taken after the test direct voltage has been applied for $1 \mathrm{~min}$ [19]. For the 21 slot 16 pole V-shape PM ISG machine, the peak phase voltage $\left(\widehat{V}_{\text {phase }}=200\right.$ Volts at $\left.2000 \mathrm{rpm}\right)$ is less than 1000 Volts meaning that Mega-ohm test voltage is 500 Volts. The static motor analyser shown in Fig. 2 has been used to carry out IR tests.

A surge test is based on applying a high current impulse to a winding using a fast rise time that will induce a voltage difference between adjacent loops of wire within the winding [20]. If the voltage difference between the magnet wires is high enough, an arc occurs between the wires. The arc can be detected by observing a shift in the surge waveform. The surge waveform is directly related to coil's inductance as internal capacitance of the instrument and coil inductance form an LC type circuit with a resonant frequency $\left(f_{\text {res }}\right)[20]$ :

$$
f_{\text {res }}=\frac{1}{2 \pi \sqrt{L C}}
$$

The LC tank circuit responds to the surge pulse with a ringing or damped sinusoidal waveform pattern. The frequency of surge waveform is dependent on coil inductance. Any variation in the coil inductance will alter the frequency of the wave pattern which will cause a distinct shift on the waveform. A reduction in inductance occurs due to turn to turn faults in a coil because inductance is related to the number of turns in the winding as stated:

$$
L \propto N^{2}
$$

A winding with a short between adjacent turns would have an inductance of:

$$
L \propto(N-1)^{2}
$$

The percentage change in inductance can therefore be written as:

$$
\Delta L=\frac{N^{2}-(N-1)^{2}}{N^{2}} \times 100
$$

The response of surge waveform identifies a turn to turn short by

- A distinct surge waveform shift between healthy coil and faulty coil

- A voltage amplitude reduction on the waveform as it is a function of: $V=L(d i / d t)$

Since compression of the ISG stator windings might lead to turn to turn short, surge tests have also been performed using a Static Motor Analyser. The test voltage based on IEEE 43 voltage standards is found to be $1400 \mathrm{~V}$.

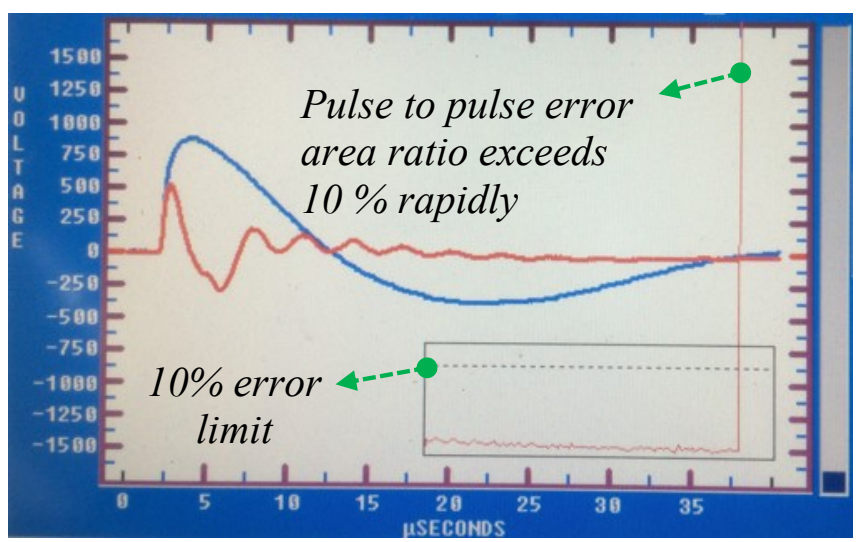

Fig. 14. Faulty condition during 1400 Volts surge test due to turn to turn short; time [0-40 $\mu$ seconds]

As shown in Fig. 14, the surge waveforms are different from each other showing that surge tests run on lead 1 and lead 2 of a winding detect a turn to turn fault in one of the compressed ISG coils which was hence omitted from the lifetime (aging) tests.

\section{Accelerated Life Tests}

Under normal service conditions, it may take several years for the insulation to fail [8]. However, accelerated test conditions are an alternative model to estimate the life time characteristics of the insulations under thermal, electrical or humidity stresses. This technique is useful due to its effectiveness, timeliness and cost effectiveness [21].

Accelerated life tests can be performed on a certain AWG wire gauge with a specific type of insulations such as polyimide, polyester-imide or polyester enamelled copper wires. In this work, an experimental process has been set up and statistical methods are employed to estimate the life time characteristics of the compressed ISG coils under thermal stress.

\subsection{Accelerated Life Test System}

A model that predicts time-to-fail as a function of operating stresses is known as an acceleration model. A set of pressed ISG coils at similar slot fill factors can be considered to be samples of the experiment. Faulty specimens (coils) must be excluded from the data set.

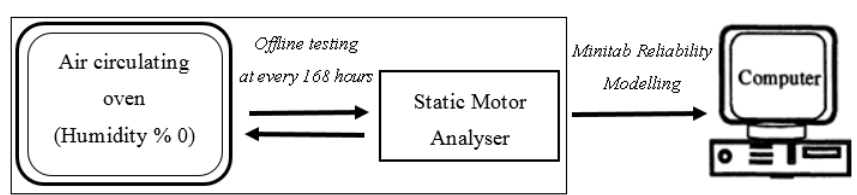

Fig. 15. Schematic of the accelerated life tests system

In Fig. 15, a schematic of the accelerated life testing system used is shown, including an air circulating oven that provides temperature and humidity control. Humidity was set to zero (in percent) since single stress (i.e. temperature) model is employed for the experiment. Off-line insulation resistance and high voltage surge tests have been conducted to inspect if the coils are healthy. Any failure in the coils due to thermal aging has been recorded in terms of time interval since exact time to failure is not known due to the fact that the off-line tests are not continuous. 


\subsection{Arrhenius - Weibull Life Model}

Different types of life models can be used to estimate the life characteristics of the pressed coils using statistical methods after collecting data from the aging experiments. These life models are useful to calculate the life time at service level conditions. Statistical distributions such as Log-normal distribution, Weibull distribution are also needed to analyse test results. The main purpose of statistical distributions is to quantify the normal amount of variation in an outcome.

Here, the Arrhenius-Weibull statistical method [10] has been employed to find a relationship between failure time of compressed windings and unreliability at certain accelerated temperatures. Also, a regression model can be derived to estimate how long the insulation will last at a given machine operating temperature when coils are prepressed. Using the outcome of statistical data after performing thermal aging tests in an environmental chamber, the life expectancy of compressed windings can be revealed. As it is not realistic to maintain life test indefinitely, aging tests were suspended before failure - so exact failure time could not be recorded as insulation failure has not been detected yet. In this case, advanced statistical methods, known as data censoring (i.e. suspension of data), are required to treat this condition.

\subsection{Parameter Estimation for Arrhenius - Weibull Life Model}

The Arrhenius life stress model is formulated by assuming life is proportional to the inverse reaction rate of the process as given [10]:

$$
L(V)=C e^{\frac{B}{V}}
$$

where $L$ represents a quantifiable life measure (i.e. mean life), $V$ is the level of stress (e.g. temperature in ${ }^{\circ} \mathrm{K}$ ), $C$ is one of the model parameters to be determined $(C>0)$. $B$ is another model parameter to be determined.

The probability density function (pdf) for the 2-parameter Weibull distribution is given by:

$$
f(t)=\frac{\beta}{\eta}\left(\frac{t}{n}\right)^{\beta-1} e^{-\left(\frac{t}{\eta}\right)^{\beta}}
$$

By setting $\eta=L(V)=C e^{\frac{B}{V}}$ and substituting for $\eta$ in the Weibull distribution equation, Arrhenius - Weibull model pdf can be obtained as given [10]:

$$
f(t, V)=\frac{\beta}{C e^{\frac{B}{V}}}\left(\frac{t}{C e^{\frac{B}{V}}}\right)^{\beta-1} e^{-\left(\frac{t}{C e^{\frac{B}{V}}}\right)^{\beta}}
$$

The parameter estimation can be carried out by using Maximum Likelihood Estimation Method. Maximum likelihood is one of the methods to estimate parameters (i.e. $\beta, B$ and $C$ ) in statistical models. Parameter estimation is crucial in accelerated life models. The maximum likelihood estimation function was not given here as it can be found in [10] which considers data censoring. The logarithmic regression model can be attained using the relationship between temperature and failure time for the coil insulation system.

\section{Experimental Results}

In Fig. 16, the variation of insulation resistances for 5-conventional and 5-compressed windings during the aging at $175^{\circ} \mathrm{C}$ is given. It is clear that compressed coils at $175^{\circ} \mathrm{C}$ lose their dielectric strength much quickly. Nonetheless, random wound conventional coils as described in Fig. 16 (fj) stay healthy in aging tests since the thermal class of the insulation system is $200^{\circ} \mathrm{C}$ which is well above the aging test temperature. The control unit results (i.e. conventional coils) at $175^{\circ} \mathrm{C}$ indicate that there is no need to repeat aging tests at lower accelerated tests temperatures for the conventional windings.

The compressed ISG coils have been aged at $175^{\circ} \mathrm{C}$, $160^{\circ} \mathrm{C}$ and $140^{\circ} \mathrm{C}$ for a minimum of 49 days and off-line turn to turn and turn to ground wall insulation tests have been performed every 168 hours ( 7 days) to monitor insulation resistance and catch failure time intervals in hours (hr). The overall results are shown in Table 4.

Table 4 Interval Censored and Right Censored time to failure data from the experiments

\begin{tabular}{|c|c|c|c|c|}
\hline $\begin{array}{c}\text { Temp } \\
\left({ }^{\circ} \mathbf{C}\right)\end{array}$ & $\begin{array}{c}\text { Arrhenius } \\
\text { Temp }\end{array}$ & $\begin{array}{c}\text { Failure } \\
\text { Interval } \\
\text { Start (hr) }\end{array}$ & $\begin{array}{c}\text { Failure } \\
\text { Interval } \\
\text { End (hr) }\end{array}$ & Frequency \\
\hline 175 & 25.894 & 168 & 336 & 2 \\
\hline 175 & 25.894 & 336 & 504 & 1 \\
\hline 175 & 25.894 & 1182 & $*$ & 2 \\
\hline 160 & 26.791 & 672 & 840 & 1 \\
\hline 160 & 26.791 & 840 & 1008 & 1 \\
\hline 160 & 26.791 & 1182 & $*$ & 3 \\
\hline 140 & 28.087 & 1008 & 1176 & 1 \\
\hline 140 & 28.087 & 1512 & 1686 & 1 \\
\hline 140 & 28.087 & 1686 & $*$ & 3 \\
\hline $\begin{array}{l}* \\
\text { denotes that a number of coils is right censored (suspended) } \\
\text { implying that no insulation failure recorded within the time period } \\
\text { of the aging experiments. }\end{array}$ \\
\hline
\end{tabular}

The failure criterion is that turn to ground wall insulation resistance must be higher than $5 \mathrm{M} \Omega$ as reported in IEEE 43-2000 standards. Turn to turn short has not been observed for any coil surge tested throughout the thermal aging period, implying that the main reason of failure is the reduction of dielectric strength between the coil and ground wall.

The frequency column in Table 4 indicates the number of failures recorded within a given time interval. The pure experimental data given in Table 4 is sufficient to estimate life expectancy of the on-tooth compressed coils.

The experimental time to failure data collected from ' 3 Phase' Accelerated Life Tests at $140^{\circ} \mathrm{C}, 160^{\circ} \mathrm{C}$ and $175^{\circ} \mathrm{C}$ have been used to predict life expectancy of the ontooth compressed coils. Three different temperate points enable to extrapolate the temperature vs life plot to estimate the life expectancy of the compressed ISG coils at operating temperature which is found to be $138^{\circ} \mathrm{C}$ from $3 \mathrm{D}$ thermal FE simulations as reported in Fig. 12(b). Arrhenius-Weibull life model parameters for the conducted aging tests are tabulated in Table 5. 


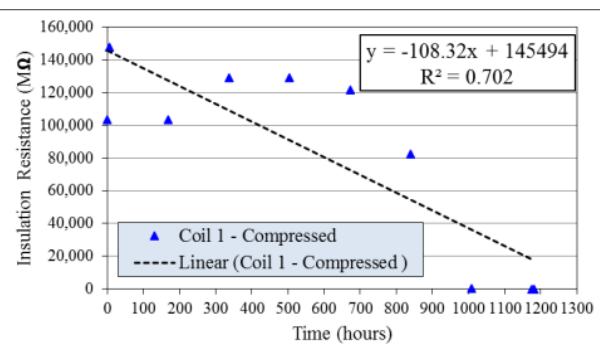

(a)

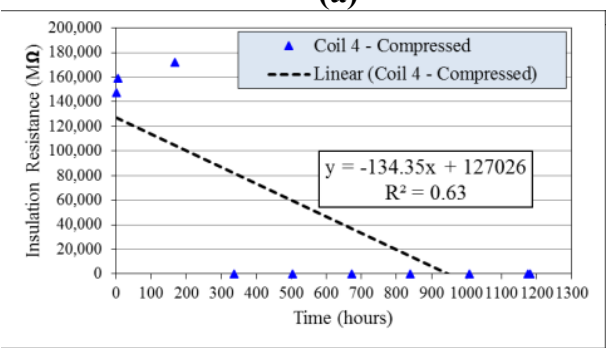

(d)

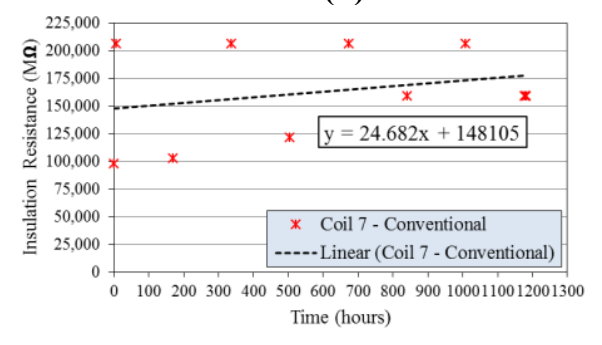

(g)

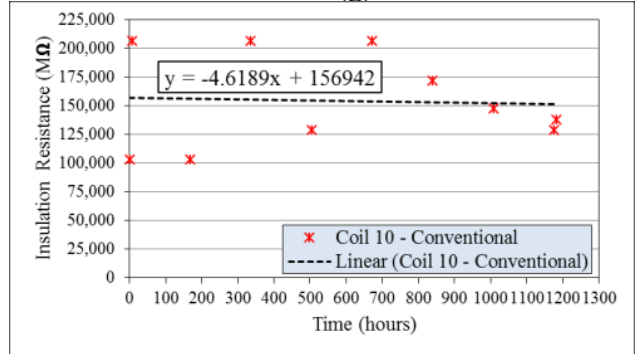

(j)

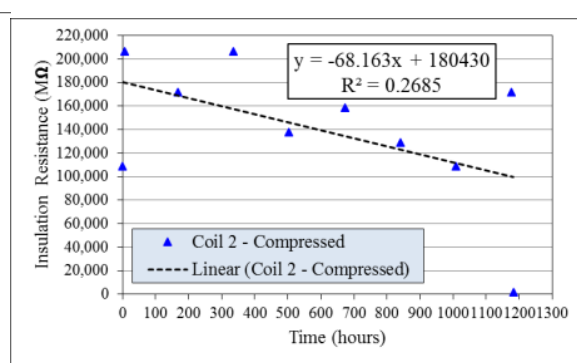

(b)

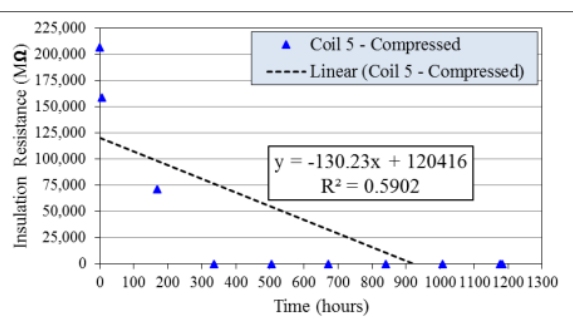

(e)

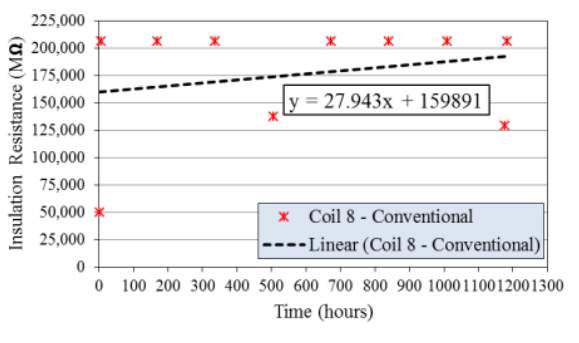

(h)

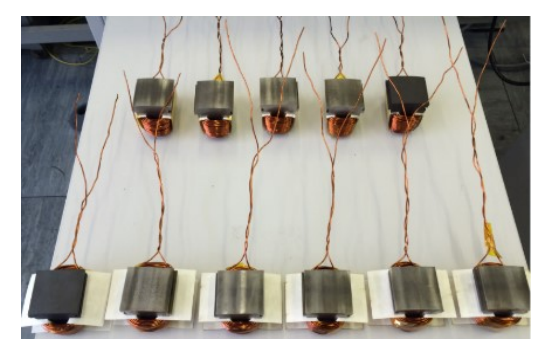

(k)

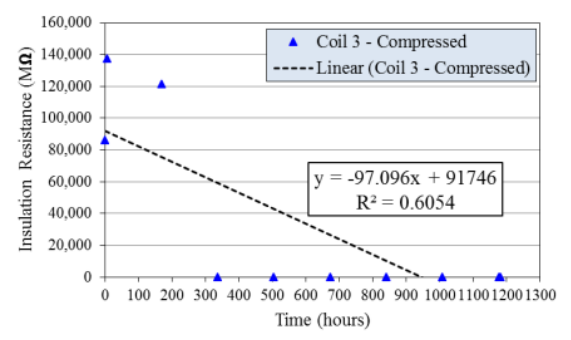

(c)

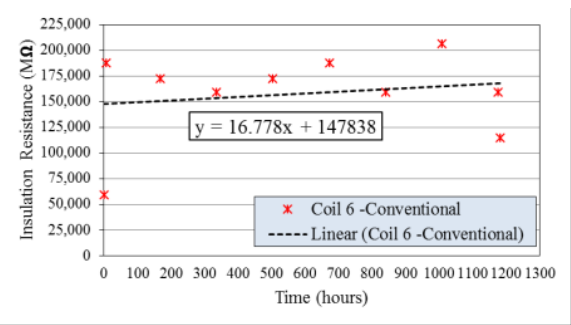

(f)

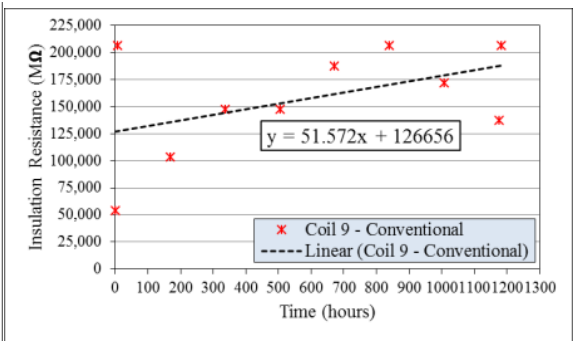

(i)

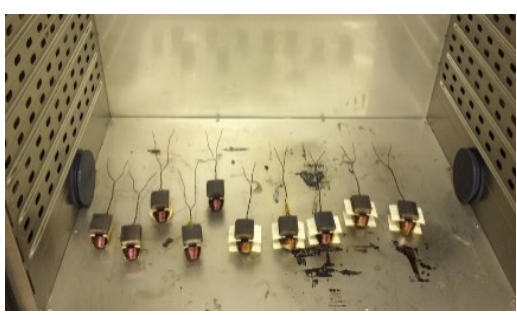

(I)

Fig. 16. (a-e) Insulation resistance of compressed coils at $175^{\circ} \mathrm{C}$ for 49 days; ( $\boldsymbol{f}$-j) Insulation resistance of conventional coils at $175^{\circ} \mathrm{C}$ for 49 days; (k) Compressed and conventional coil samples ; (l) Aging in an environmental chamber

Table 5 Arrhenius-Weibull Life Data Analysis

\begin{tabular}{|c|c|c|c|c|}
\hline \multicolumn{2}{|c|}{ Acceleration variable: } & \multicolumn{3}{|c|}{ Temperature } \\
\hline \multicolumn{2}{|c|}{ Distribution : } & \multicolumn{3}{|c|}{ Weibull } \\
\hline \multicolumn{2}{|c|}{ Estimation: } & \multicolumn{3}{|c|}{ Maximum Likelihood } \\
\hline \multicolumn{2}{|c|}{$\begin{array}{l}\text { Relationship with } \\
\text { accelerating variable: }\end{array}$} & \multicolumn{3}{|c|}{ Arrhenius } \\
\hline \multicolumn{2}{|c|}{ Right censored data: } & \multicolumn{3}{|c|}{8} \\
\hline \multicolumn{2}{|c|}{ Interval censored data: } & \multicolumn{3}{|c|}{7} \\
\hline \multicolumn{2}{|c|}{ Number of data (coils): } & \multicolumn{3}{|c|}{15} \\
\hline \multicolumn{5}{|c|}{ Regression Table } \\
\hline Predictor & Coefficient & $\begin{array}{l}\text { Standard } \\
\text { Error }\end{array}$ & $\begin{array}{c}95 \% \\
\text { Normal } \\
\text { Confiden } \\
\text { ce } \\
\text { Interval - } \\
\text { Lower }\end{array}$ & $\begin{array}{c}95 \% \\
\text { Normal } \\
\text { Confiden } \\
\text { ce } \\
\text { Interval - } \\
\text { Upper }\end{array}$ \\
\hline Intercept & -4.83446 & 7.633 & -19.79 & 10.12 \\
\hline Temperature & 0.456644 & 0.286 & -0.10 & 1.01 \\
\hline Shape & 1.59653 & 0.548 & 0.81 & 3.12 \\
\hline
\end{tabular}

From the regression data given in Table 5, the coefficients for the regression model are obtained. For a Weibull distribution, this model describes the relationship between temperature and failure time for the insulation as given by [22]:

$$
\begin{aligned}
\log _{e}(\text { failureT }) & =-4.83446 \\
& +0.456644(\text { Arrh.Temp }) \\
& +\left(\frac{1}{1.59653}\right) \varepsilon_{p}
\end{aligned}
$$

where $\varepsilon_{p}$ is the $\mathrm{p}^{\text {th }}$ percentile of the standard extreme value distribution. Arrhenius temperature is calculated as given [22]:

Arrhenius Temp $=\frac{11604.83}{\text { Temperature in }{ }^{\circ} \mathrm{C}+273.16}$

The probability plot given in Fig. 17 can help determine if the distribution at each level of accelerating variable (i.e. temperature) is appropriate or not. If the fitted lines are approximately parallel, the probability model 
becomes more accurate. According to Fig. 17, 99\% (probability) of the compressed ISG coils fail in 8190.35 hours (mean life) if they operate at $138^{\circ} \mathrm{C}$.

The $50^{\text {th }}$ percentile is a good estimate of insulation life expectancy. Therefore, 2501.34 hours life in average is expected from the coils running at $138^{\circ} \mathrm{C}$. This states that the dielectric strength of turn to ground wall insulation for the compressed ISG windings is significantly affected negatively by on-tooth compression method.

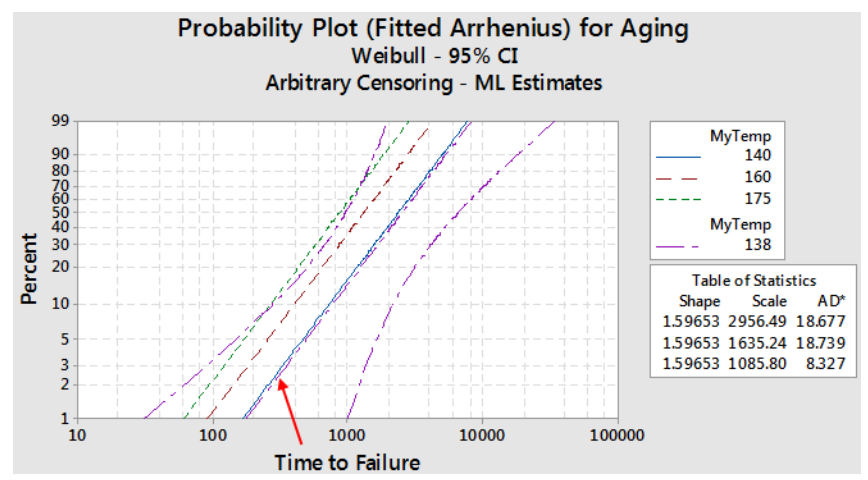

(a)

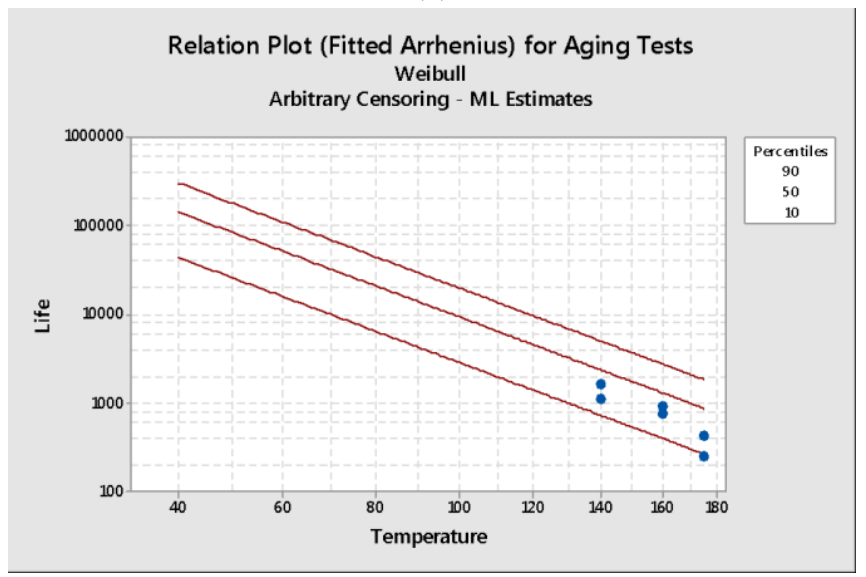

(b)

Fig. 17. Arrhenius-Weibull probability plot (a), life time extrapolation to lower temperatures (b)

\section{Arrhenius Equation based Linear Regression Analysis}

In Section 6, the life expectancy of the compressed coils was estimated via Arrhenius-Weibull reliability model that takes the right censored data into account. A more straightforward method to estimate the life expectancy without including any probabilistic distribution model such as Weibull is described here. This method is based on Arrhenius equation with normal distribution and mean life of the ISG coils in each thermal aging experiment has been used to estimate the insulation life of the compressed windings According to Arrhenius formula;

$$
L=C e^{\frac{B}{V}}
$$

Equation (14) is recalled in (19). This can be written in a linear form as given:

$$
\log _{10} L=\log _{10} C+\left(\log _{10} e\right) \cdot\left(\frac{B}{V}\right)
$$

Assuming that;

$$
N=\text { number of test temperatures }
$$

$$
\begin{aligned}
& Y=\log _{10} L \\
& a=\log _{10} C
\end{aligned}
$$

$X=1 / V-$ Reciprocal Of The Test Temperature in ${ }^{\circ} \mathrm{K}$

$$
b=\log _{10} e \cdot B
$$

Then

$$
Y=a+b X
$$

The parameters $a$ and $b$ can be calculated from the method of least squares from the following:

$$
\begin{gathered}
a=\frac{\left(\sum_{N} Y-b \sum_{N} X\right)}{N} \\
b=\frac{\left(N \sum_{N} X Y-\sum_{N} X \sum_{N} Y\right)}{\left(N \sum_{N} X^{2}-\left(\sum_{N} X\right)\right)^{2}}
\end{gathered}
$$

If $a$ and $b$ are known, any required life can be calculated as given in (21). The values of ' $a$ ' and ' $b$ '-slope are calculated to be 3276.71 and -4.75 from Table 6 , below. After that log-linear life expectancy is plotted in Excel Spreadsheet as a linear function as shown in Fig. 18.

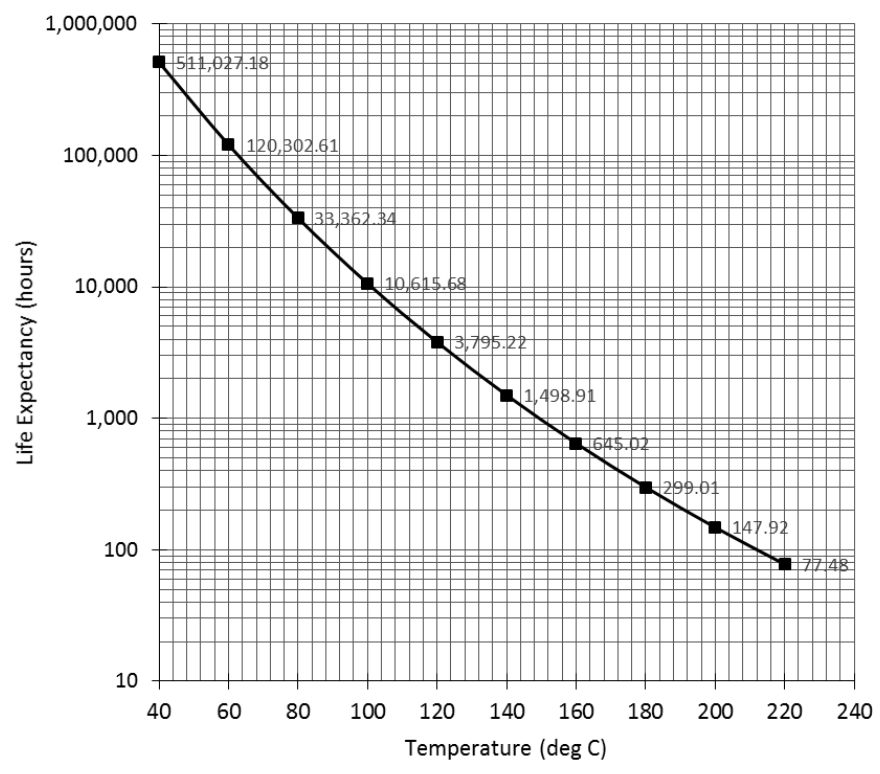

Fig. 18. Life expectancy of the compressed ISG coils by neglecting censored data

At $138^{\circ} \mathrm{C}$, the ISG machine will stay healthy for 1638.15 hours according to log - linear thermal endurance plot given in Fig. 18. This estimation certainly gives less life expectancy compared to Arrhenius-Weibull reliability analysis (2501.34 hours) since right censored-suspended data cannot be included in this mathematical model. 
Table 6 Arrhenius equation parameter calculations using the method of least squares

\begin{tabular}{|c|c|c|c|c|c|c|}
\hline Temp & $X=1 / V$ & $X^{2}=1 / V^{2}$ & $L(V)^{*}$ & $Y=\log _{10} L$ & $X Y=\left(\log _{10} L\right) / V$ & $Y^{2}$ \\
\hline $140^{\circ} \mathrm{C}$ & 0.002420428 & $5.85847 \mathrm{E}-06$ & 1345.5 & 3.128883702 & 0.007573239 & 9.789913221 \\
\hline $160^{\circ} \mathrm{C}$ & 0.002308669 & $5.32995 \mathrm{E}-06$ & 840 & 2.924279286 & 0.006751193 & 8.551409343 \\
\hline $175^{\circ} \mathrm{C}$ & 0.002231396 & $4.97913 \mathrm{E}-06$ & 308 & 2.488550717 & 0.005552941 & 6.192884669 \\
\hline$\sum$ & 0.006960493 & $1.61676 \mathrm{E}-05$ & & 8.541713705 & 0.019877374 & 24.53420723 \\
$N=3$ & & & & & & \\
\hline
\end{tabular}

* The average time to failure is computed by only considering the failed ISG coils - the censored data was not included in the calculations.

It is shown that on-tooth compressed coils at 0.72 slot fill factor gives a significant reduction in the life expectancy in comparison to conventional random wound coils. The authors need to emphasise that this is not because turn to turn short between the adjacent wires but this is due to seriously damaged Nomex 410 slot liners as they experience pressure up to $14-20$ tonnes. After terminating the aging tests, some of the sample coils have been unwound to investigate the deformation in slot liners. This is shown in Fig. 19.

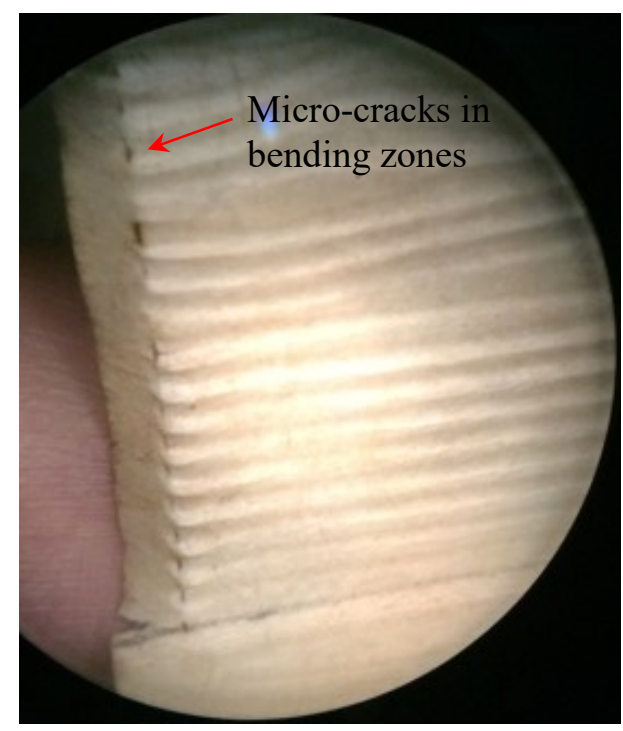

Fig. 19. Plastic deformation in $0.25 \mathrm{~mm}$ thick Nomex 410 slot liners during compression - aged 840 hours

\section{Reliability of Commercial Round Magnet Wires}

ASTM D 2307 standard determines the thermal index of magnet wires. The magnet wires used in the ISG stator windings are of temperature class $200^{\circ} \mathrm{C}$. This means that it has 20,000 hour life at maximum $200^{\circ} \mathrm{C}$. This information is based on ASTM D 2307 specimen testing methodology. The preparation of specimens are given in [23]. The specimens for aging tests usually consist of twisted pair of wires with film insulations and a holder.

However, some of the magnet wires with a class of $200^{\circ} \mathrm{C}$ used in random wound un-pressed ISG windings fail at $175^{\circ} \mathrm{C}$ as shown in Fig. 20. This was noticed when wires have been un-wound from the tooth and the static motor analyser could not catch the fault. This shows that commercial magnet wires might not be operated at their temperature class and also emphasise that keeping the temperature low for stator windings is vital.

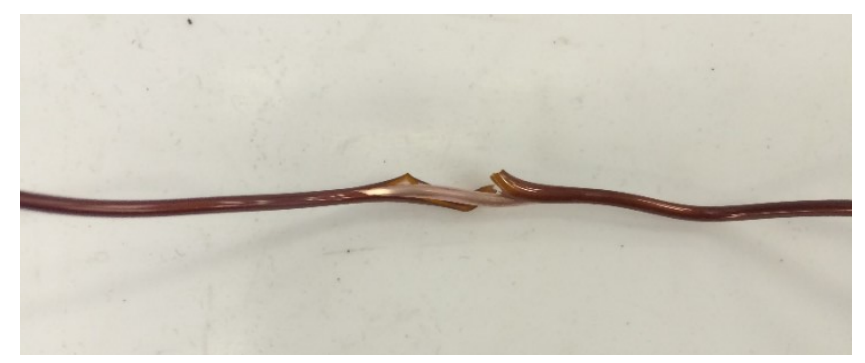

Fig. 20. Damaged magnet wire after 49 day thermal aging at $175^{\circ} \mathrm{C}$ - not a compressed coil

\section{Conclusion}

In this work, accelerated life tests for the compressed and conventional stator windings with a thermal class of $200^{\circ} \mathrm{C}$ are described. A three stage $\left(140^{\circ} \mathrm{C}, 160^{\circ} \mathrm{C}\right.$ and $175^{\circ} \mathrm{C}$ ) thermal aging tests of the ISG coils enable to perform Arrhenius-Weibull life model. The employed statistical model proves that on-tooth coil pressing reduce the life expectancy dramatically due to reduced turn to ground wall dielectric strength. This could not be prevented even with two layer of insulation system (Kapton HN film $0.075 \mathrm{~mm}+$ Nomex $410-0.25 \mathrm{~mm})$. It is reported that if the windings are directly pressed on the tooth, the life expectancy will be about 2500 hours for the compressed ISG coils operating at $138^{\circ} \mathrm{C}$ yet it will be higher at lower temperatures. Despite the thermal advantages of coil pressing as presented in Section 3, on-tooth coil pressing harshly reduces the turn to ground wall dielectric insulation strength.

Therefore, this suggests that stator windings can be pressed off tooth (on a dummy tooth) and then they can be placed into the original stator with un-damaged slot liners. This observation is in line with the aging test results since turn to turn short in the ISG coils has never caught by static motor analyser during the experiments. In other words, the compression of coils usually damage external insulation layers rather than magnet wire coatings. Moreover, the accuracy of the statistical analysis given in this work might be improved by increasing the number of specimens entering the experiments.

\section{References}

[1] J. R. Hendershot, "MotorSolve analysis of the 2010 Toyota Prius Traction Motor," ed. Chicago: Hendershot 2015 Copyright, 2015. 
[2] Z. Huang, F. J. Márquez-Fernández, Y. Loayza, A. Reinap, and M. Alaküla, "Dynamic thermal modeling and application of electrical machine in hybrid drives," in 2014 International Conference on Electrical Machines (ICEM), 2014, pp. 21582164.

[3] P. G. Dickinson, "Application of Soft Magnetic Composites in Electrical Machines," PhD Thesis, Newcastle University, United Kingdom, 2002.

[4] A. G. Jack, B. C. Mecrow, P. G. Dickinson, D. Stephenson, J. S. Burdess, J. N. Fawcett, et al., "Permanent magnet machines with powdered iron cores and pre-pressed windings," in Conference Record of the 1999 IEEE Industry Applications Conference. Thirty-Forth IAS Annual Meeting (Cat. No.99CH36370), 1999, pp. 97-103 vol.1.

[5] M. C. Kulan, N. J. Baker, and J. D. Widmer, "Design and Analysis of Compressed Windings for a Permanent Magnet Integrated Starter Generator," IEEE Transactions on Industry Applications, 2017.

[6] J. D. Widmer, C. M. Spargo, G. J. Atkinson, and B. C. Mecrow, "Solar Plane Propulsion Motors With Precompressed Aluminum Stator Windings," IEEE Transactions on Energy Conversion, vol. 29, pp. 681-688, 2014.

[7] M. C. Kulan and N. J. Baker, "Thermal Aging Investigation of Random Wound Compressed Stator Windings," in 9th International Conference on Power Electronics, Machines and Drives (PEMD 2018), 2018.

[8] G. C. Stone, E. A. Boulter, I. Culbert, and H. Dhirani, Electrical insulation for rotating machines: design, evaluation, aging, testing, and repair vol. 21: John Wiley \& Sons, 2004.

[9] M. C. Kulan, N. J. Baker, J. D. Widmer, and S. Lambert, "Mechanical and Thermal Properties of Compressed Stator Windings," in IET International Conference on Power Electronics Machines and Drives (PEMD 2016).

[10] (2015, 02/07/2017). Accelerated Life Testing Reference [E-book]. Available: http://www.synthesisplatform.net/references/Accel erated_Life_Testing_Reference.pdf

[11] M. C. Kulan, N. J. Baker, and J. D. Widmer, "Design of a high fill factor permanent magnet integrated starter generator with compressed stator windings," in 2016 XXII International Conference on Electrical Machines (ICEM), 2016, pp. 15131519.

[12] A. Boglietti, E. Carpaneto, M. Cossale, M. Popescu, D. Staton, and S. Vaschetto, "Equivalent thermal conductivity determination of winding insulation system by fast experimental approach," in Electric Machines \& Drives Conference (IEMDC), 2015 IEEE International, 2015, pp. 1215-1220.

[13] A. Boglietti, E. Carpaneto, M. Cossale, A. L. Borlera, D. Staton, and M. Popescu, "Electrical machine first order short-time thermal transients model: Measurements and parameters evaluation," in Industrial Electronics Society, IECON 2014-40th Annual Conference of the IEEE, 2014, pp. 555-561.

[14] M. Rosu, P. Zhou, D. Lin, D. M. Ionel, M. Popescu, F. Blaabjerg, et al., Multiphysics Simulation by
Design for Electrical Machines, Power Electronics and Drives vol. 66: John Wiley \& Sons, 2017.

[15] S. W. Churchill and H. H. S. Chu, "Correlating equations for laminar and turbulent free convection from a horizontal cylinder," International journal of heat and mass transfer, vol. 18, pp. 1049-1053, 1975.

[16] G. D. Demetriades, H. Z. De La Parra, E. Andersson, and H. Olsson, "A real-time thermal model of a permanent-magnet synchronous motor," IEEE Transactions on Power Electronics, vol. 25, pp. 463-474, 2010.

[17] G. Kylander, "Thermal modelling of small cage induction motors," Ph.D. dissertation, School of Electr. Comput. Eng., Chalmers Univ. Technol., Goteborg, Sweden, 1995.

[18] J. Lindstom, "Thermal model of a permanent magnet motor for a hybrid electric vehicle," $\mathrm{Ph} . \mathrm{D}$. Thesis, Dept. Power Eng., Chalmers Univ. Technol., Goteborg- Sweden, 1999.

[19] "IEEE Recommended Practice for Testing Insulation Resistance of Electric Machinery Redline," IEEE Std 43-2013 (Revision of IEEE Std 43-2000) - Redline, pp. 1-75, 2014.

[20] (2013). SKF Static Motor Analyzer User Manual [Online].

[21] S. Grzybowski, S. Bandaru, N. Kota, and C. F. King, "Lifetime characteristics of magnet wires under pulse voltage [wire insulation multistress effects]," in Electrical Insulation and Dielectric Phenomena, 2004. CEIDP'04. 2004 Annual Report Conference on, 2004, pp. 145-148.

[22] (2017, 05/12/2017). Minitab 17.0 Support. Available: https://support.minitab.com/enus/minitab/18/help-and-how-to/modelingstatistics/reliability/how-to/accelerated-lifetesting/before-you-start/overview/

[23] A. International, "Standard Test Method for Thermal Endurance of Film-Insulated Round Magnet Wire D2307," ed. West Conshohocken, PA, United States: ASTM International, 2013. 